\title{
Synthesis and microwave dielectric properties of Ca substituted $\mathrm{SrLa}_{4} \mathrm{Ti}_{4.93} \mathrm{Zr}_{0.07} \mathrm{O}_{17}$ ceramics
}

\author{
ABDUL MANAN ${ }^{1} *$ and IBRAHIM QAZI ${ }^{2}$ \\ ${ }^{1}$ Department of Physics, University of Science and Technology, Bannu, 28100 KPK, Pakistan \\ ${ }^{2}$ Department of Materials Science and Engineering, Institute of Space Technology, Islamabad 44000, Pakistan
}

MS received 15 February 2013; revised 18 April 2013

\begin{abstract}
Microwave dielectric ceramics in $\mathrm{Sr}_{1-x} \mathrm{Ca}_{x} \mathrm{La}_{4} \mathrm{Ti}_{4.93} \mathrm{Zr}_{0.07} \mathrm{O}_{17}(0 \leq x \leq 0.5)$ composition series were processed via a solid-state sintering rout. $X$-ray diffraction revealed single phase ceramics. Ca substitutions for $\mathrm{Sr}$ tuned $\tau_{\mathrm{f}}$ towards zero with increased $Q_{\mathrm{u}} f_{\mathrm{o}}$ values. In the present study, $\varepsilon_{\mathrm{r}} \sim 55, Q_{\mathrm{u}} f_{\mathrm{o}} \sim 11960 \mathrm{GHz}$ and $\tau_{\mathrm{f}} \sim 5.2 \mathrm{ppm} /{ }^{\circ} \mathrm{C}$ were achieved for the composition with $x=0.3$.
\end{abstract}

Keywords. Patch antenna; theoretical density; phase; ceramics.

\section{Introduction}

Extensive research has been carried out in the last three decades on dielectric ceramics due to their unique electrical properties which make them suitable candidates as dielectric resonators for microwave based wireless telecommunication industry by reducing the size and cost of filters and antennas in the circuit. Ideal materials for commercial applications as dielectric resonators (DRs) for base stations require high relative electric permittivity $\left(\varepsilon_{\mathrm{r}}>24\right)$, near-zero temperature coefficient of resonant frequency $\left(\tau_{\mathrm{f}} \sim 0 \mathrm{ppm} /{ }^{\circ} \mathrm{C}\right)$, and a high unloaded quality factor, generally reported as a product with the frequency $\left(f_{\mathrm{o}}\right)$ at which it is measured $\left(Q_{\mathrm{u}} f_{\mathrm{o}} \approx 30,000 \mathrm{GHz}\right)$ (Reaney and Idles 2006). For certain applications, e.g. antennas, the values of $\tau_{\mathrm{f}}$ and $Q_{\mathrm{u}} f_{\mathrm{o}}$ can be compromised to $\pm 10 \mathrm{ppm} /{ }^{\circ} \mathrm{C}$ and $>10,000 \mathrm{GHz}$ (Sebastian 2008).

Layered perovskites with general formula, $\mathrm{A}_{n} \mathrm{~B}_{n} \mathrm{O}_{3 n+2}$ $(n=5)$, have received much attention due to their high dielectric performance for applications in patch antenna (Chen and Tsai 2008; Chen and Zeng 2009; Wang et al 2010).

$\mathrm{SrLa}_{4} \mathrm{Ti}_{5} \mathrm{O}_{17}$ was reported to have $\varepsilon_{\mathrm{r}} \sim 39 \cdot 1, Q_{\mathrm{u}} f_{\mathrm{o}} \sim$ $14200 \mathrm{GHz}$ and $\tau_{\mathrm{f}} \sim 58 \mathrm{ppm} /{ }^{\circ} \mathrm{C}$ (Demsar et al 2008). However, in another study, $\varepsilon_{\mathrm{r}} \sim 61, Q_{\mathrm{u}} f_{\mathrm{o}} \sim 9969 \mathrm{GHz}$ and $\tau_{\mathrm{f}} \sim 117 \mathrm{ppm} /{ }^{\circ} \mathrm{C}$ was reported for $\mathrm{SrLa}_{4} \mathrm{Ti}_{5} \mathrm{O}_{17}$ (Iqbal and Manan 2012a, b). This difference in the microwave dielectric properties of $\mathrm{SrLa}_{4} \mathrm{Ti}_{5} \mathrm{O}_{17}$ could be attributed to the different processing conditions employed in two separate studies milling for $0.5 \mathrm{~h}$ and sintering at $1580{ }^{\circ} \mathrm{C}$ for $20 \mathrm{~h}$ with relative density of $92 \%$ in the study carried out by Demsar et al (2008) and milling for $24 \mathrm{~h}$ and sintering at $1500{ }^{\circ} \mathrm{C}$ for $4 \mathrm{~h}$ with relative density of $94.5 \%$ in the

\footnotetext{
*Author for correspondence (drmanan82@yahoo.com)
}

study carried out by Iqbal and Manan (2012a, b). The high positive $\tau_{\mathrm{f}}$ precluded its application at microwave frequencies. $\mathrm{Nd}$ substitutions for $\mathrm{La}$ in $\mathrm{SrLa}_{4} \mathrm{Ti}_{5} \mathrm{O}_{17}$ tuned $\tau_{\mathrm{f}}$ towards $0 \mathrm{ppm} /{ }^{\circ} \mathrm{C}$ with $\varepsilon_{\mathrm{r}}>50$ but at the cost of decreasing $Q_{\mathrm{u}} f_{\mathrm{o}}$ respectively (Manan and Iqbal 2012). In another study, partial substitution of $\mathrm{Zr}$ for $\mathrm{Ti}$ in $\mathrm{SrLa}_{4} \mathrm{Ti}_{5} \mathrm{O}_{17}\left(\mathrm{SrLa}_{4} \mathrm{Ti}_{4.93} \mathrm{Zr}_{0.07} \mathrm{O}_{17}\right)$ decreased $\tau_{\mathrm{f}}$ to $72 \mathrm{ppm} /$ ${ }^{\circ} \mathrm{C}$ with slight increase in $Q_{\mathrm{u}} f_{\mathrm{o}}$ from 9969 to $10,046 \mathrm{GHz}$ (Iqbal and Manan 2012a). The high positive $\tau_{\mathrm{f}}$ of $\mathrm{SrLa}_{4} \mathrm{Ti}_{4.93} \mathrm{Zr}_{0.07} \mathrm{O}_{17}$ also precluded its application at microwave frequencies. In a previous study, Ca substitution for $\mathrm{Sr}$ tuned $\tau_{\mathrm{f}}$ of $\mathrm{Sr}_{5} \mathrm{Nb}_{4} \mathrm{TiO}_{17}$ towards zero along with increase in $Q_{\mathrm{u}} f_{\mathrm{o}}$ value (Manan et al 2011). Therefore, aim of the present study was to investigate the microwave dielectric properties of $\mathrm{Sr}_{1-x} \mathrm{Ca}_{x} \mathrm{La}_{4} \mathrm{Ti}_{4.93} \mathrm{Zr}_{0.07} \mathrm{O}_{17}$ solid solution and assess their suitability as temperature stable microwave ceramics.

\section{Experimental}

$\mathrm{Sr}_{1-x} \mathrm{Ca}_{x} \mathrm{La}_{4} \mathrm{Ti}_{4.93} \mathrm{Zr}_{0.07} \mathrm{O}_{17} \quad(0 \leq x \leq 0 \cdot 5) \quad$ ceramics were fabricated via solid-state mix oxide route. Laboratory reagent-grade $\mathrm{SrCO}_{3}$ (Aldrich, $99+\%$ ) and $\mathrm{CaCO}_{3}$ (Aldrich, $99+\%$ ) dried at $\sim 185{ }^{\circ} \mathrm{C}$ and $\mathrm{La}_{2} \mathrm{O}_{3}$ (Aldrich, 99.95\%), $\mathrm{ZrO}_{2}$ (Aldrich, 99.95\%), and $\mathrm{TiO}_{2}$ (Aldrich, Anatase, $99+\%$ ) were dried at $900{ }^{\circ} \mathrm{C}$ for $24 \mathrm{~h}$ to remove adsorbed moisture. The dried carbonates and oxides were weighted in stoichiometric ratios and were wet ballmilled for $24 \mathrm{~h}$ in the disposable polyethylene mill jars using $\mathrm{Y}$-toughened $\mathrm{ZrO}_{2}$ balls as grinding medium and isoprapanol as liquid. The slurries were dried in a drying oven at $\sim 95{ }^{\circ} \mathrm{C}$ for $24 \mathrm{~h}$. The powders were sieved and calcined at $1350{ }^{\circ} \mathrm{C}$ for $6 \mathrm{~h}$ at heating/cooling rates of $5{ }^{\circ} \mathrm{C} / \mathrm{min}$. The calcined powder samples were remilled for $4 \mathrm{~h}$. the calcined powders were pressed into 4- to 5-mm 
thick and $10-\mathrm{mm}$ in diameter at $100 \mathrm{MPa}$. The pellets were placed on platinum foil and sintered at 1450 to $1590{ }^{\circ} \mathrm{C}$ for $4 \mathrm{~h}$ at heating/cooling rates of $5{ }^{\circ} \mathrm{C} / \mathrm{min}$. The sintered samples were crushed into fine powders. Phase analyses of the pulverized sintered pellets were carried out using X-ray diffractometer (model D500) operating at $30 \mathrm{kV}$ and $40 \mathrm{~mA}$ at $1 \% \mathrm{~min}$ from $2 \theta=10$ to $70^{\circ}$ with step size of $0.02^{\circ}$.

For lattice parameters measurement, XRD was performed using STOE PSD X-ray diffractometer with $\operatorname{CuK} \alpha(\lambda=1.540598 \AA)$ operating at $30 \mathrm{kV}$ and $40 \mathrm{~mA}$ at $1 \%$ min from $2 \theta=10$ to $70^{\circ}$ with step size of $0 \cdot 01^{\circ}$. STOE WinXPOW software (version 1.06, STOE and Cie GmbH, Darmstadt, Germany) was used to determine and refine the lattice parameters for the new unit cell resulting from the substitution of $\mathrm{Ca}$ for $\mathrm{Sr}$ in $\mathrm{Sr}_{1-x} \mathrm{Ca}_{x} \mathrm{LaTi}_{4.93} \mathrm{Zr}_{0.07} \mathrm{O}_{17}$. For microstructure examination, optimal dense pellets were cut into halves and were well-polished before thermal etching at temperature $10 \%$ less than their corresponding sintering temperature at heating and cooling rates of $5^{\circ} \mathrm{C} / \mathrm{min}$. The thermally etched surfaces were gold coated to avoid charging in SEM. A JEOL 6400 SEM (JEOL, Japan) operating at $20 \mathrm{kV}$ was used.

Microwave dielectric properties were measured using Agilent network analyser (R3767CH, Agilent, USA) via the cavity method. Cylindrical samples were placed at the centre of Au-coated cavity made of brass on low-loss quartz single crystal to avoid conduction loss from the walls of the cavity. The temperature coefficient of resonant frequency $\left(\tau_{\mathrm{f}}\right)$ was measured in the range $20-70{ }^{\circ} \mathrm{C}$ using (1).

$$
\tau_{\mathrm{f}}=\left(f_{2}-f_{1}\right) /\left[f_{1}\left(T_{2}-T_{1}\right)\right],
$$

where $f_{1}$ and $f_{2}$ are the initial and final resonant frequencies at 20 and $70{ }^{\circ} \mathrm{C}$, respectively.

\section{Results and discussion}

The relative density $\left(\rho_{\mathrm{r}}\right)$ of $\mathrm{Sr}_{1-x} \mathrm{Ca}_{x} \mathrm{La}_{4} \mathrm{Ti}_{4 \cdot 93} \mathrm{Zr}_{0 \cdot 07} \mathrm{O}_{17}$ $(0 \leq x \leq 0 \cdot 5)$ ceramics as a function of sintering temperature is shown in figure 1. Previous study revealed that substitution of an ion with lower ionic radius for an ion with larger ionic radius increases the sintering temperature (Sreemoolanadhan et al 1995). In the present study, the optimum sintering temperature is increased for about $40{ }^{\circ} \mathrm{C}$ with $\mathrm{Ca}$ substitution for $\mathrm{Sr}$. All the ceramics were sintered more than $95 \%$ of their theoretical density.

XRD patterns recorded at room temperature for $\mathrm{Sr}_{1-x}$ $\mathrm{Ca}_{x} \mathrm{La}_{4} \mathrm{Ti}_{4.93} \mathrm{Zr}_{0.07} \mathrm{O}_{17} \quad(0 \leq x \leq 0.5)$ ceramics sintered at their optimum sintering temperatures for $4 \mathrm{~h}$ are shown in figure 2. The $d$ values and intensities corresponding to XRD peaks of the compositions with $x=0-0.5$ matched with the one reported for $\mathrm{SrLa}_{4} \mathrm{Ti}_{5} \mathrm{O}_{17}$ (PDF\#27-1059). There was no evidence of any secondary phase in each composition within the in-house XRD detection limits.
XRD peaks for the compositions with $x=0 \cdot 1-0.5$ shifted towards higher diffraction angles, i.e. smaller $d$ values due to smaller ionic radius of $\mathrm{Ca}^{2+}(1 \cdot 34 \AA)$ than $\mathrm{Sr}^{2+}$ (1.44 $\AA$ ) for 12-coordination (Shannon 1976). The unit cell parameters refined by the least squares method are observed to decrease with $\mathrm{Ca}$ concentration as given in table 1 . The corresponding unit cell volume and theoretical density are observed to decrease for the investigated ceramics and also compared in table 1.

The secondary electron images (SEIs) from thermally etched and gold coated surfaces of optimally sintered $\mathrm{Sr}_{1-x}$ $\mathrm{Ca}_{x} \mathrm{La}_{4} \mathrm{Ti}_{4.93} \mathrm{Zr}_{0.07} \mathrm{O}_{17}(0 \leq x \leq 0 \cdot 5)$ ceramics are shown in figure 3 . Highly dense microstructure for each composition is observed and consisted with their relative density

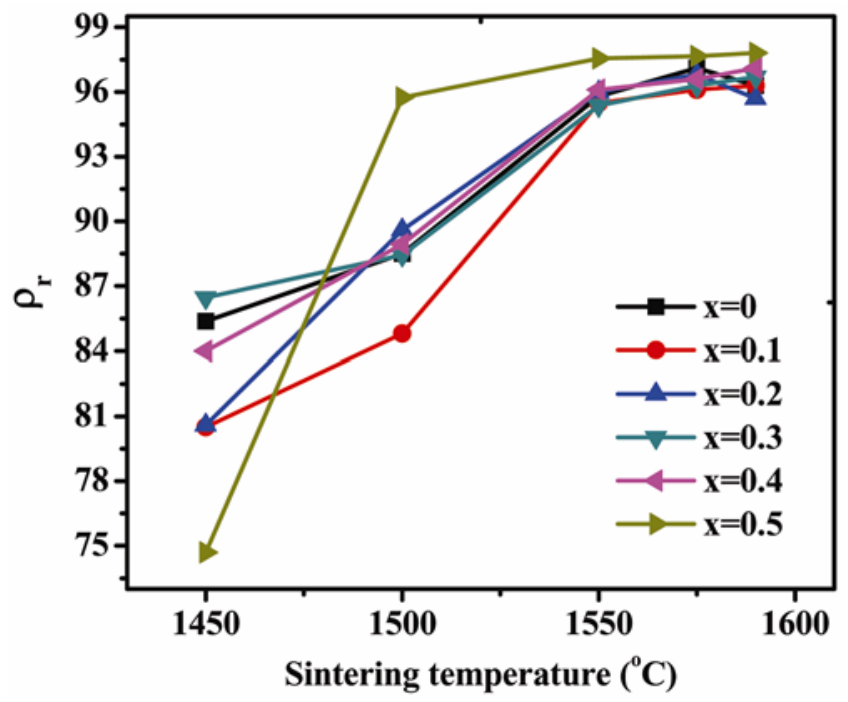

Figure 1. Variation in relative density $\left(\rho_{\mathrm{r}}\right)$ of $\mathrm{Sr}_{1-x} \mathrm{Ca}_{x} \mathrm{La}_{4}$ $\mathrm{Ti}_{4.93} \mathrm{Zr}_{0.07} \mathrm{O}_{17}(0 \leq x \leq 0 \cdot 5)$ ceramics as a function of sintering temperature.

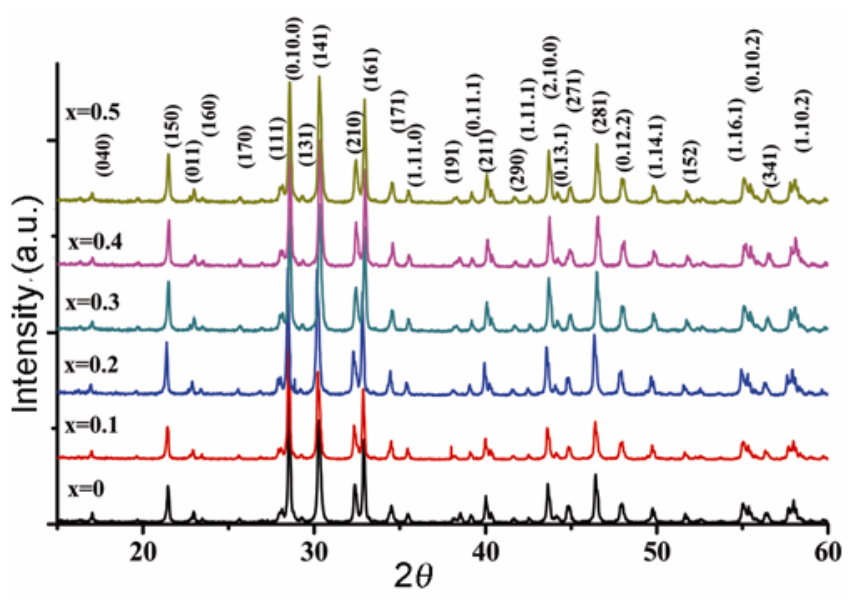

Figure 2. XRD patterns from $\mathrm{Sr}_{1-x} \mathrm{Ca}_{x} \mathrm{La}_{4} \mathrm{Ti}_{4 \cdot{ }^{9} 3} \mathrm{Zr}_{0.07} \mathrm{O}_{17}$ $(0 \leq x \leq 0 \cdot 5)$ ceramics sintered at optimum sintering temperatures, showing formation of a single phase ceramics for each composition. 
Table 1. Processing temperatures, apparent densities, theoretical and relative densities and microwave dielectric properties of $\mathrm{Sr}_{1-x} \mathrm{Ca}_{x} \mathrm{La}_{4} \mathrm{Ti}_{4 \cdot 93} \mathrm{Zr}_{0.07} \mathrm{O}_{17}(0 \leq x \leq 0 \cdot 5)$ ceramics.

\begin{tabular}{lcccccccccc}
\hline$(x)$ & $\mathrm{S} . \mathrm{T}\left({ }^{\circ} \mathrm{C}\right)$ & $a(\AA)$ & \multicolumn{1}{c}{$b(\AA)$} & $c(\AA)$ & $V\left(\AA^{3}\right)$ & $\rho_{\mathrm{th}}\left(\mathrm{g} \mathrm{cm}^{-3}\right)$ & $\rho_{\mathrm{r}}$ & \multicolumn{1}{c}{$\varepsilon_{\mathrm{r}}$} & $Q_{\mathrm{u}} f_{\mathrm{o}}(\mathrm{GHz})$ & $\tau_{\mathrm{f}}\left(\mathrm{ppm} /{ }^{\circ} \mathrm{C}\right)$ \\
\hline 0 & 1575 & $5 \cdot 551(3)$ & $31 \cdot 316(13)$ & $3 \cdot 9095(18)$ & $679 \cdot 6$ & $5 \cdot 65$ & $97 \cdot 1$ & $58 \cdot 2$ & 10800 & $73 \cdot 5$ \\
0.1 & 1590 & $5 \cdot 547(3)$ & $31 \cdot 308(6)$ & $3 \cdot 9063(4)$ & $678 \cdot 3$ & $5 \cdot 64$ & $96 \cdot 3$ & $57 \cdot 1$ & 11150 & $50 \cdot 1$ \\
0.2 & 1575 & $5 \cdot 540(10)$ & $31 \cdot 301(7)$ & $3 \cdot 9024(9)$ & $676 \cdot 7$ & $5 \cdot 63$ & $96 \cdot 8$ & $56 \cdot 3$ & 11500 & $25 \cdot 2$ \\
0.3 & 1590 & $5 \cdot 535(12)$ & $31.296(8)$ & $3 \cdot 8997(13)$ & $675 \cdot 5$ & $5 \cdot 62$ & $96 \cdot 7$ & $55 \cdot 0$ & 11960 & $5 \cdot 4$ \\
0.4 & 1590 & $5 \cdot 529$ & 31.293 & $3 \cdot 8981$ & 674.4 & $5 \cdot 60$ & $97 \cdot 1$ & $53 \cdot 9$ & 12345 & $-10 \cdot 3$ \\
0.5 & 1590 & $5 \cdot 526$ & 31.289 & $3 \cdot 8972$ & $673 \cdot 9$ & $5 \cdot 59$ & $97 \cdot 8$ & $52 \cdot 8$ & 12750 & $-22 \cdot 3$ \\
\hline
\end{tabular}

S.T, Sintering temperature, $\rho_{\mathrm{r}}$, relative density.
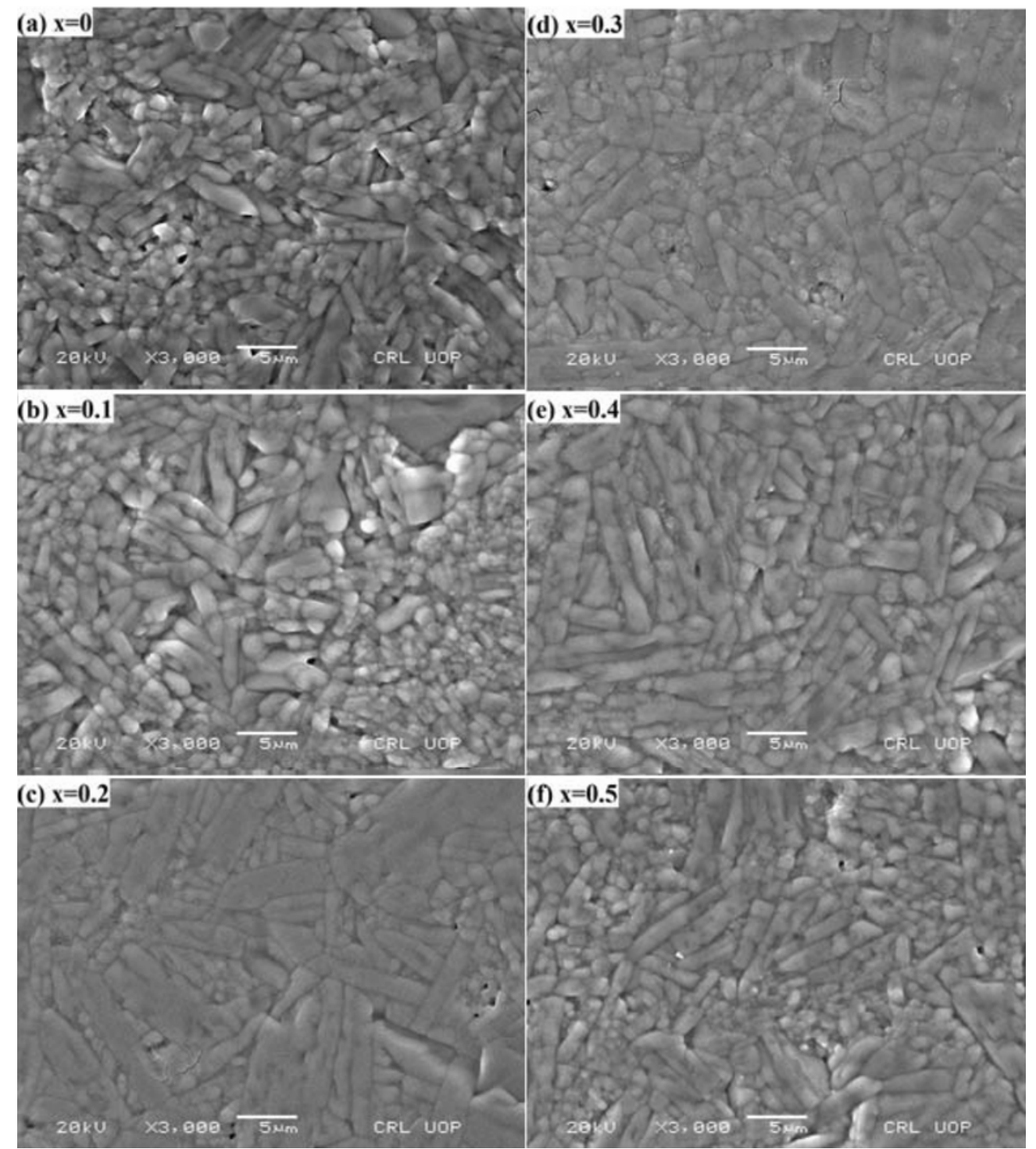

Figure 3. SEIs of $\mathrm{Sr}_{1-x} \mathrm{Ca}_{x} \mathrm{La}_{4} \mathrm{Ti}_{4.93} \mathrm{Zr}_{0.07} \mathrm{O}_{17}(0 \leq x \leq 0.5)$ ceramics showing highly dense microstructure for each composition.

data (figure 1). The typical elongated grain morphology of layered perovskites was observed for each composition.

The variation in $\varepsilon_{\mathrm{r}}$ and $\tau_{\mathrm{f}}$ for $\mathrm{Sr}_{1-x} \mathrm{Ca}_{x} \mathrm{La}_{4} \mathrm{Ti}_{4 \cdot 93} \mathrm{Zr}_{0.07} \mathrm{O}_{17}$ $(0 \leq x \leq 0 \cdot 5)$ ceramics sintered at their optimum sintering temperatures for $4 \mathrm{~h}$ in air as a function of $\mathrm{Ca}$ content is shown in figure 4 . Both $\varepsilon_{\mathrm{r}}$ and $\tau_{\mathrm{f}}$ are observed to decrease from 58 to 52 and 73.5 to $-22.3 \mathrm{ppm} /{ }^{\circ} \mathrm{C}$ with increasing $\mathrm{Ca}^{2+}$ concentration from 0 to $0 \cdot 5$, respectively. The decrease in $\varepsilon_{\mathrm{r}}$ is presumably due to lower ionic polarizabilty of $\mathrm{Ca}^{2+}\left(3 \cdot 16 \AA^{3}\right)$ compared with $\mathrm{Sr}^{2+}\left(4 \cdot 24 \AA^{3}\right)$ (Shannon 1993). The monotonous decrease in $\varepsilon_{\mathrm{r}}$ suggests 
that there are no structural phase transitions in the solid solution as a function of increasing $x$. It has been suggested that $\varepsilon_{\mathrm{r}}$ is directly proportional to ' $\tau_{\mathrm{f}}$ ' in the absence of structural phase transition as a function of $x$ within the solid solution (Reaney and Idles 2006). $\mathrm{Ca}^{2+}$ has a smaller ionic radius than $\mathrm{Sr}^{2+}$ but substitution results in only a small decrease in the average cuboctahedral ion radius which principally contain $\mathrm{La}^{3+}$ ions. The tolerance factor of the perovskite-like blocks in the layered structured is low enough to induce rotations of the $\mathrm{O}$ octahedra at high temperature and substitution of $\mathrm{Ca}$ for $\mathrm{Sr}$ has little impact on their type and magnitude. $Q_{\mathrm{u}} f_{\mathrm{o}}$ $(\mathrm{GHz})$ value was increased from 10,800 to $12,750 \mathrm{GHz}$ (figure 5) as $\mathrm{Ca}$ concentration was increased from 0 to

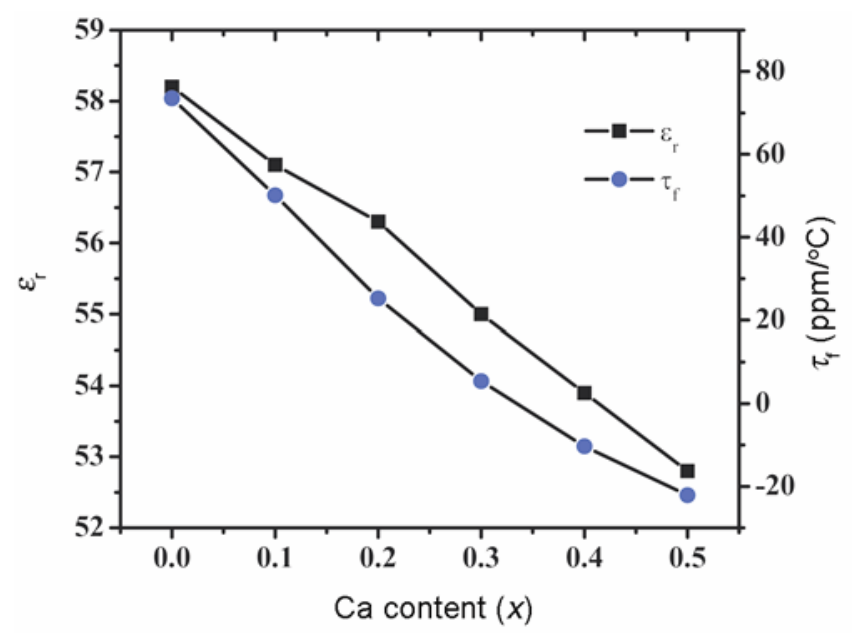

Figure 4. Variation in $\varepsilon_{\mathrm{r}}$ and $\varepsilon_{\mathrm{f}}$ with $\mathrm{Ca}$ content for $\mathrm{Sr}_{1-x}$ $\mathrm{Ca}_{x} \mathrm{La}_{4} \mathrm{Ti}_{4.93} \mathrm{Zr}_{0.07} \mathrm{O}_{17}(0 \leq x \leq 0 \cdot 5)$ ceramics, showing a decrease in both $\varepsilon_{\mathrm{r}}$ and $\tau_{\mathrm{f}}$ with increasing $x$.

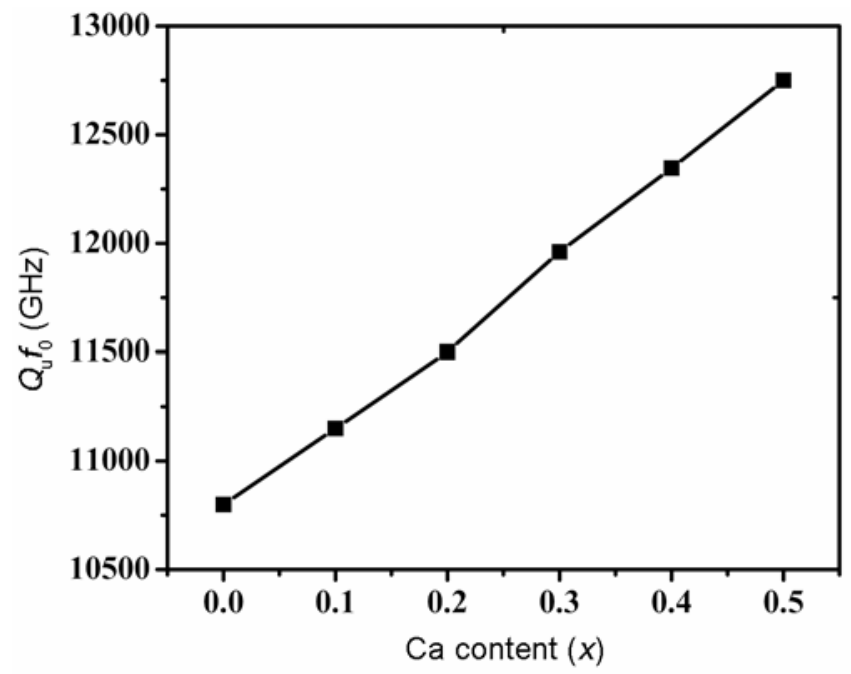

Figure 5. Variation in $Q_{\mathrm{u}} f_{\mathrm{o}}$ with Ca content $(x)$ for $\mathrm{Sr}_{1-x}$ $\mathrm{Ca}_{x} \mathrm{La}_{4} \mathrm{Ti}_{4.93} \mathrm{Zr}_{0.07} \mathrm{O}_{17}(0 \leq x \leq 0.5)$ ceramics, showing increase in $Q_{\mathrm{u}} f_{\mathrm{o}}$ value with increasing $x$.

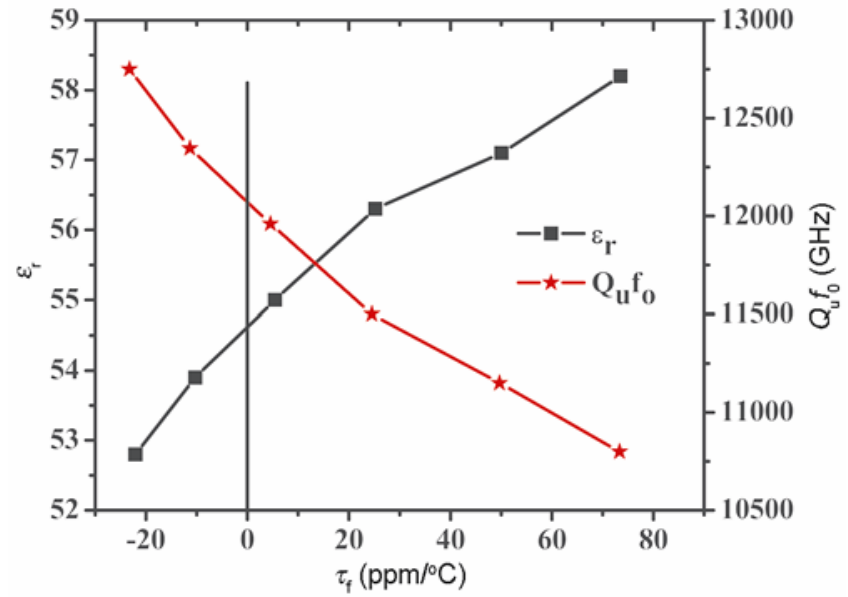

Figure 6. $\varepsilon_{\mathrm{r}}$ and $Q_{\mathrm{u}} f_{\mathrm{o}}$ vs $\tau_{\mathrm{f}}$ for $\mathrm{Sr}_{1-x} \mathrm{Ca}_{x} \mathrm{La}_{4} \mathrm{Ti}_{4 \cdot 93} \mathrm{Zr}_{0.07} \mathrm{O}_{17}$ $(0 \leq x \leq 0 \cdot 5)$ ceramics showing that $\tau_{\mathrm{f}} \sim 0 \mathrm{ppm} /{ }^{\circ} \mathrm{C}$ corresponds to $\varepsilon_{\mathrm{r}} \sim 54.5$ and $Q_{\mathrm{u}} f_{\mathrm{o}} \sim 12000 \mathrm{GHz}$.

$0 \cdot 5$. It is generally, reported that as atomic size difference at the A-site of the perovskite structure decreases, the lattice strain decreases which in turn decreases the loss of the material and vice versa (Fang et al 2008; Fang et al 2010). Since the size of $\mathrm{Ca}<\mathrm{Sr}$ therefore, the substitutions of $\mathrm{Ca}$ for $\mathrm{Sr}$ decreased the size difference at the A-site and hence increased the $Q_{\mathrm{u}} f_{\mathrm{o}}$ value. The analysis of the present result indicates that $\tau_{\mathrm{f}} \sim 0 \mathrm{ppm} /{ }^{\circ} \mathrm{C}$ corresponds to $\varepsilon_{\mathrm{r}} \sim 54.5$ and $Q_{\mathrm{u}} f_{\mathrm{o}} \sim 12,000 \mathrm{GHz}$ as shown in figure 6 .

\section{Conclusions}

Dielectric ceramics in $\mathrm{Sr}_{1-x} \mathrm{Ca}_{x} \mathrm{La}_{4} \mathrm{Ti}_{4.93} \mathrm{Zr}_{0.07} \mathrm{O}_{17} \quad(0 \leq x$ $\leq 0 \cdot 5)$ series were prepared via conventional solid-state mix oxide route. XRD revealed the formation of a single phase ceramics for each composition sintered in air for $4 \mathrm{~h}$ in the temperature range $1450-1590{ }^{\circ} \mathrm{C}$. The substitution of $\mathrm{Ca}$ for $\mathrm{Sr}$ tuned $\tau_{\mathrm{f}}$ towards zero with increased $Q_{\mathrm{u}} f_{\mathrm{o}}$ value. $\varepsilon_{\mathrm{r}} \sim 55, Q_{\mathrm{u}} f_{\mathrm{o}} \sim 11,960 \mathrm{GHz}$ and $\tau_{\mathrm{f}} \sim 5 \mathrm{ppm} /{ }^{\circ} \mathrm{C}$ were achieved for the composition with $x=0.3\left(\mathrm{Sr}_{0.7} \mathrm{Ca}_{0.3}\right.$ $\left.\mathrm{La}_{4} \mathrm{Ti}_{4.93} \mathrm{Zr}_{0.07} \mathrm{O}_{17}\right)$ in the present study. $Q_{\mathrm{u}} f_{\mathrm{o}}$ is too low for use as dielectric resonator but ceramics in $\mathrm{Sr}_{1-x}$ $\mathrm{Ca}_{x} \mathrm{La}_{4} \mathrm{Ti}_{4.93} \mathrm{Zr}_{0.07} \mathrm{O}_{17}(0 \leq x \leq 0.5)$ solid solution may find application as cores in dielectrically loaded antennas or patch antenna.

\section{Acknowledgements}

The authors acknowledge the financial support of the Higher Education Commission of Pakistan, under International Support Initiative Programme (IRSIP) and electroceramics group in assisting the authors at the Electroceramics and Composite Laboratory, Department of Materials Science and Engineering, University of Sheffield (UK). 


\section{References}

Chen Y C and Tsai J M 2008 Jpn. J. Appl. Phys. 477959

Chen Y C and Zeng Y W 2009 Microwave Opt. Tech. Lett. 51 98

Demsar K, Skapin S D, Meden A and Suvorov D 2008 Acta Chim. Slov. 55966

Fang L, Men S S, Zhang H, Liu Q and Liu H F 2008 J. Electroceram. 21137

Fang L, Li C, Peng X, Hu C and Wu B 2010 J. Am. Ceram. Soc. 931884

Iqbal Y and Manan A 2012a J. Mater. Sci: Mater. Electron. 23 1848
Iqbal Y and Manan A 2012b J. Electron. Mater. 412393

Manan A, Iqbal Y and Qazi I 2011 J. Mater. Sci. 463415

Manan A and Iqbal Y 2012 Mater. Res. Bull. 47883

Reaney I M and Idles D $2006 \mathrm{~J}$. Am. Ceram. Soc. 89 2068

Sebastian M T 2008 Dielectric materials for wireless communications (London: Elsevier Publications)

Shannon R D 1976 Acta Cryst. A32 751

Shannon R D 1993 J. Appl. Phys. 73348

Sreemoolanadhan H, Isaac J, Sebastian M T, Jose K A and Mohanan P 1995 Ceram. Inter. 21385

Wang S C, Chen Y C and Chen K C 2010 Ferroelectric. Lett. Sect. 3783 